\title{
BMJ
}

\section{Randomised trial of glutamine, selenium, or both, to supplement parenteral nutrition for critically ill patients}

\author{
Peter I D Andrews, professor of critical care, consultant, ${ }^{1,2}$ Alison Avenell, clinical senior lecturer, ${ }^{3}$ David W \\ Noble, consultant, ${ }^{4}$ Marion K Campbell, director, ${ }^{3}$ Bernard L Croal, consultant, ${ }^{5}$ William G Simpson, \\ consultant, ${ }^{5}$ Luke D Vale, professor of health technology assessment, ${ }^{3,6}$ Claire G Battison, trial manager, ${ }^{1}$ \\ David J Jenkinson, research fellow in medical statistics, ${ }^{3}$ Jonathan A Cook, methodologist ${ }^{3}$ and the SIGNET \\ (Scottish Intensive care Glutamine or seleNium Evaluative Trial) Trials Group
}

\begin{abstract}
${ }^{1}$ Centre for Clinical Brain Sciences, University of Edinburgh, Edinburgh EH4 2XU, UK

${ }^{2}$ Critical Care, Western General Hospital, Lothian University Hospitals Division, Edinburgh EH4 2XU, UK

${ }^{3}$ Health Services Research Unit, University of Aberdeen, Aberdeen AB25 2ZD, UK
\end{abstract}

${ }^{4}$ Department of Anaesthetics and Intensive Care, Aberdeen Royal Infirmary, Aberdeen AB25 2ZN

${ }^{5}$ Department of Clinical Biochemistry, Aberdeen Royal Infirmary, Aberdeen

${ }^{6}$ Health Economics Research Unit, University of Aberdeen, Aberdeen Correspondence to: P J D Andrews p.andrews@ed.ac.uk

Cite this as: $B M J$ 2011;342:d1542 doi:10.1136/bmi.d1542

\section{ABSTRACT}

Objective To determine whether inclusion of glutamine, selenium, or both in a standard isonitrogenous, isocaloric preparation of parenteral nutrition influenced new infections and mortality among critically ill patients. Design Randomised, double blinded, factorial, controlled trial.

Setting Level 2 and 3 (or combined) critical care units in Scotland. All 22 units were invited, and 10 participated. Participants 502 adults in intensive care units and high dependency units for $\geq 48$ hours, with gastrointestinal failure and requiring parenteral nutrition.

Interventions Parenteral glutamine $(20.2 \mathrm{~g} /$ day) or selenium $(500 \mu \mathrm{g} /$ day), or both, for up to seven days. Main outcome measures Primary outcomes were participants with new infections in the first 14 days and mortality. An intention to treat analysis and a prespecified analysis of patients who received $\geq 5$ days of the trial intervention are presented. Secondary outcomes included critical care unit and acute hospital lengths of stay, days of antibiotic use, and modified SOFA (Sepsisrelated Organ Failure Assessment) score.

Results Selenium supplementation did not significantly affect patients developing a new infection (126/251 V $139 / 251$, odds ratio 0.81 ( $95 \% \mathrm{Cl} 0.57$ to 1.15$)$ ), except for those who had received $\geq 5$ days of supplementation (odds ratio 0.53 (0.30 to 0.93$)$ ). There was no overall effect of glutamine on new infections (134/250 v 131/ 252 , odds ratio 1.07 ( 0.75 to 1.53$)$ ), even if patients received $\geq 5$ days of supplementation (odds ratio 0.99 (0.56 to 1.75$)$ ). Six month mortality was not significantly different for selenium $(107 / 251 v 114 / 251$, odds ratio 0.89 ( 0.62 to 1.29$))$ or glutamine $(115 / 250 v 106 / 252$, 1.18 ( 0.82 to 1.70$)$ ). Length of stay, days of antibiotic use, and modified SOFA score were not significantly affected by selenium or glutamine supplementation.

Conclusions The primary (intention to treat) analysis showed no effect on new infections or on mortality when parenteral nutrition was supplemented with glutamine or selenium. Patients who received parenteral nutrition supplemented with selenium for $\geq 5$ days did show a reduction in new infections. This finding requires confirmation.

Trial registration Current Controlled Trials ISRCTN87144826

\section{INTRODUCTION}

Infection and sepsis are major causes of increased mortality, morbidity, and resource use in intensive care units. They are associated with both illness and drug related impairment of the immune system, compounded by malnutrition often observed in patients admitted to critical care. ${ }^{1}$

The enteral feeding route is preferred for critically ill patients because of its reduced costs and risk of infective complications. ${ }^{2}$ Parenteral nutrition, however, has an important role because many intensive care patients have gastrointestinal dysfunction. ${ }^{3}$

Recent systematic reviews have suggested that parenteral administration of glutamine to critically ill patients reduces mortality (risk ratio 0.71 (95\% confidence interval 0.55 to 0.92 )) and new infections (risk ratio $0.76(0.62$ to 0.93$)) .{ }^{4}$ Selenium supplementation in critical illness has also been shown to reduce mortality (risk ratio 0.84 (0.67 to 1.05$)$ ) but with little effect on infections (risk ratio 0.93 (0.70 to 1.23$)) .{ }^{4}$ However, these systematic reviews are based on small trials, many of poor quality. These drawbacks, and concerns that there may be publication and reporting bias, mean that large, well conducted randomised trials are still required for definitive results.

We therefore conducted a large randomised controlled trial examining whether the inclusion of glutamine, selenium, or both in a standard isonitrogenous, isocaloric preparation of parenteral nutrition influenced the rate of new infections and mortality in critically ill patients.

\section{METHODS}

The full protocol for the trial is described elsewhere. ${ }^{5}$ 


\section{Setting}

Department of Health level 2 and 3 intensive care units or mixed adult units run by an intensivist were eligible. All 22 Scottish intensive care units were invited to participate, and 10 agreed. Scottish Intensive Care Society's Audit Group's (SICSAG) website and annual report describe each site in detail (www.scottishintensi vecare.org.uk/sicsag/annual\%20report/index.htm).

\section{Participants}

Patients were eligible if they were expected to be on intensive care and high dependency units for $\geq 48$ hours, were aged $\geq 16$ years, and required $\geq 50 \%$ of their nutritional requirements to be met by parenteral nutrition. Pregnant women and people whose expected stay in the UK was $<6$ months were not eligible. Patients with estimated glomerular filtration rate $<10 \mathrm{ml} / \mathrm{min}$ and not receiving renal replacement therapy were also excluded.

\section{Design}

We used a $2 \times 2$ factorial design ${ }^{67}$ to test whether glutamine and selenium, either alone or in combination, were effective. A remote telephone computer system generated random allocation to one of four possible groups with minimisation ${ }^{8}$ on trial centre, age $(<65$ or $\geq 65$ years), sex, patient group (medical or surgical (including trauma)), and nutritional status (undernourished, normal, or obese by subjective clinical assessment $\left.{ }^{9}\right)$. Patients, clinicians, and investigators

\begin{tabular}{|c|c|c|c|c|c|}
\hline \multicolumn{6}{|c|}{ Potential participants $(\mathrm{n}=1134)$} \\
\hline & & \multicolumn{4}{|c|}{$\begin{array}{l}\text { Excluded }(n=559) \text { : } \\
\text { Failed to meet inclusion criteria }(n=506) \\
\text { Trial parenteral nutrition unavailable }(n=53)\end{array}$} \\
\hline \multicolumn{6}{|c|}{ Approached $(n=575)$} \\
\hline & & \multicolumn{4}{|c|}{ Consent not obtained $(n=73)$} \\
\hline \multicolumn{6}{|c|}{ Randomised $(\mathrm{n}=502)$} \\
\hline & 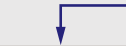 & $\uparrow$ & $\downarrow$ & $\downarrow$ & \\
\hline Parenteral nutrition: & $\begin{array}{l}\text { With } \\
\text { glutamine } \\
(n=126)\end{array}$ & $\begin{array}{l}\text { With } \\
\text { selenium } \\
(n=127)\end{array}$ & $\begin{array}{c}\text { With } \\
\text { glutamine } \\
+ \text { selenium } \\
(\mathrm{n}=124)\end{array}$ & $\begin{array}{l}\text { With } \\
\text { neither } \\
(n=125)\end{array}$ & $\begin{array}{c}\text { Total } \\
(n=502)\end{array}$ \\
\hline $\begin{array}{l}\text { Received trial parenteral nutrition: } \\
\geq 5 \text { days } \\
<5 \text { days } \\
\text { None }\end{array}$ & $\begin{array}{l}64(51 \%) \\
59(47 \%) \\
3(2 \%)\end{array}$ & $\begin{array}{c}51(40 \%) \\
71(56 \%) \\
5(4 \%)\end{array}$ & $\begin{array}{l}60(48 \%) \\
57(46 \%) \\
7(6 \%)\end{array}$ & $\begin{array}{l}55(44 \%) \\
68(54 \%) \\
2(2 \%)\end{array}$ & $\begin{array}{l}230(46 \%) \\
255(51 \%) \\
17(3 \%)\end{array}$ \\
\hline Died within 3 months & $56(44 \%)$ & $50(39 \%)$ & $49(40 \%)$ & $45(36 \%)$ & $200(40 \%)$ \\
\hline $\begin{array}{l}\text { Alive at } 3 \text { months*: } \\
\text { Completed questionnaire } \\
\text { Did not complete }\end{array}$ & $\begin{array}{c}70 \\
53(76 \%) \\
17(24 \%)\end{array}$ & $\begin{array}{c}77 \\
56(73 \%) \\
21(27 \%)\end{array}$ & $\begin{array}{c}75 \\
53(71 \%) \\
22(29 \%)\end{array}$ & $\begin{array}{c}80 \\
63(79 \%) \\
17(21 \%)\end{array}$ & $\begin{array}{c}302 \\
225(75 \%) \\
77(25 \%)\end{array}$ \\
\hline Died within 3-6 months & $4(3 \%)$ & $2(2 \%)$ & $6(5 \%)$ & $9(7 \%)$ & $21(4 \%)$ \\
\hline $\begin{array}{l}\text { Alive at } 6 \text { months }^{\star} \text { : } \\
\text { Completed questionnaire } \\
\text { Did not complete }\end{array}$ & $\begin{array}{c}66 \\
49(74 \%) \\
17(26 \%)\end{array}$ & $\begin{array}{c}75 \\
51(68 \%) \\
24(32 \%)\end{array}$ & $\begin{array}{c}\quad 69 \\
51(74 \%) \\
18(26 \%)\end{array}$ & $\begin{array}{c}71 \\
56(79 \%) \\
15(21 \%)\end{array}$ & $\begin{array}{c}281 \\
207(74 \%) \\
74(26 \%)\end{array}$ \\
\hline
\end{tabular}

* Percentages based on the number of participants alive at each time point were blinded to treatment allocation. Consent procedures followed the 2003 Mental Health (Care and Treatment, Scotland) Act. Ethical approval was obtained from the Multicentre Research Ethics Committee Scotland.

\section{Interventions}

The daily trial interventions were parenteral nutrition bag containing $(a)$ standard formulation $(12.5 \mathrm{~g}$ nitrogen, $2000 \mathrm{kcal})$, (b) glutamine formulation (12.5 g nitrogen (including 20.2 g glutamine), $2000 \mathrm{kcal}$ ), (c) standard formulation with addition of $500 \mu \mathrm{g}$ selenium, (d) glutamine formulation with addition of 500 $\mu \mathrm{g}$ selenium. Both standard and glutamine formulations were tested for long term stability in parenteral nutrition bags (1500 ml volume), and for short term stability after addition of selenium. Selenium was added by the hospital pharmacy aseptic unit. Standard additions of fluid, electrolytes, vitamins, and minerals (including low dose selenium, $\leq 50 \mu \mathrm{g}$ daily) were allowed. Additional parenteral nitrogen or energy were not allowed to be added to the bags (to retain the isonitrogenous nature of the interventions).

Trial intervention was for a maximum of seven days (on critical care units and subsequently on hospital wards). Trial parenteral nutrition was started as soon as practicable with the pharmacy. For men weighing $<60 \mathrm{~kg}$ and women weighing $<70 \mathrm{~kg}$ the volume of feed could be reduced to reflect reduced requirements. ${ }^{5}$

\section{Measures of outcome}

The primary outcomes were numbers of participants with new infections in the first 14 days after randomisation and mortality (on critical care unit, and overall at six months). Infections were defined in two ways: (a) all clinically suspected infections (primary definition) and (b) only infections confirmed in accordance with the Centers for Disease Control criteria (after review by the adjudication committee).

Other outcome measures defined a priori were length of stay on critical care unit, length of stay in acute hospital, days of antibiotic use (assessed during the 14 days after starting the trial intervention), modified Sequential Organ Failure Assessment (SOFA) score assessed over seven days (central nervous system domain removed as most patients were sedated in the critical care units and some were admitted after head injury), and serious adverse events for 14 days (excluding deaths). It was not possible to collect data on ventilator use. ${ }^{5}$

Quality of life measures (SF-12 and EQ-5D questionnaires) were collected at three and six months by post, but will be presented in a separate paper with the economic evaluation.

Information on deaths after discharge was obtained from routine data collected by the Information Services Division of the Scottish National Health Service. 


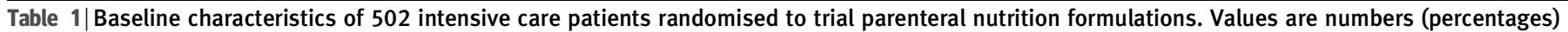
unless stated otherwise

\begin{tabular}{|c|c|c|c|c|c|c|c|c|c|}
\hline \multirow[b]{3}{*}{ Characteristic } & \multicolumn{9}{|c|}{ Trial parenteral nutrition formulations } \\
\hline & \multicolumn{4}{|c|}{ Individual formulations } & \multicolumn{4}{|c|}{ Combined groups } & \multirow[b]{2}{*}{$\begin{array}{c}\text { All } \\
(n=502)\end{array}$} \\
\hline & $\begin{array}{c}\text { Glutamine } \\
(n=126)\end{array}$ & $\begin{array}{l}\text { Selenium } \\
(n=127)\end{array}$ & $\begin{array}{l}\text { Glutamine } \\
+ \text { selenium } \\
(n=124)\end{array}$ & $\begin{array}{l}\text { Neither } \\
(n=125)\end{array}$ & $\begin{array}{c}\text { Any } \\
\text { glutamine } \\
(n=250)\end{array}$ & $\begin{array}{l}\text { Any non- } \\
\text { glutamine } \\
(n=252)\end{array}$ & $\begin{array}{l}\text { Any selenium } \\
\qquad(n=251)\end{array}$ & $\begin{array}{l}\text { Any non- } \\
\text { selenium } \\
(n=251)\end{array}$ & \\
\hline Mean (SD) age (years) & $63.2(14.5)$ & $64.5(14.2)$ & $64.5(15.7)$ & $63.1(15.3)$ & $63.8(15.1)$ & $63.8(14.7)$ & $64.5(14.9)$ & $63.1(14.8)$ & $63.8(14.9)$ \\
\hline Female & 49 (39) & $50(39)$ & $49(40)$ & $50(40)$ & $98(39)$ & $100(40)$ & $99(39)$ & 99 (39) & $198(39)$ \\
\hline Critical care unit level 3 & $114(90)$ & $116(91)$ & $108(87)$ & $109(87)$ & $222(89)$ & $225(89)$ & $224(89)$ & $223(89)$ & $447(89)$ \\
\hline Medical patient & $30(24)$ & $30(24)$ & $36(29)$ & $31(25)$ & $66(26)$ & $61(24)$ & $66(26)$ & $61(24)$ & $127(25)$ \\
\hline APACHE II score: & $(n=126)$ & $(n=127)$ & $(n=122)$ & $(n=124)$ & $(n=248)$ & $(n=251)$ & $(n=249)$ & $(n=250)$ & $(n=499)$ \\
\hline Median (IQR) & $21(16-26)$ & $20(15-25)$ & $20(16-24)$ & $20(16-25)$ & $21(16-25)$ & $20(15-25)$ & $20(16-25)$ & $21(16-25)$ & $20(16-25)$ \\
\hline Sepsis & $77 / 125(62)$ & $67 / 125(54)$ & $73 / 124(59)$ & $65 / 124(52)$ & $150 / 249(60)$ & $132 / 249(53)$ & $140 / 249(56)$ & $142 / 249(57)$ & $282 / 498(57)$ \\
\hline \multicolumn{10}{|l|}{ Nutritional status: } \\
\hline Underweight & $35(28)$ & $36(28)$ & $32(26)$ & $34(27)$ & $67(27)$ & $70(28)$ & $68(27)$ & $69(27)$ & $137(27)$ \\
\hline Normal & $69(55)$ & $69(54)$ & $71(57)$ & $72(58)$ & $140(56)$ & $141(56)$ & $140(56)$ & $141(56)$ & $281(56)$ \\
\hline Obese & $22(17)$ & $22(17)$ & $21(17)$ & 19 (15) & $43(17)$ & $41(16)$ & $43(17)$ & $41(16)$ & $84(17)$ \\
\hline Antibiotics used & $114 / 125(91)$ & $113 / 126(90)$ & $105 / 124(85)$ & $114 / 124(92)$ & $219 / 249(88)$ & $227 / 250(91)$ & $218 / 250(87)$ & $228 / 249(92)$ & $446 / 499$ (89) \\
\hline Nutrition type: & $(n=125)$ & $(n=127)$ & $(n=124)$ & $(n=124)$ & $(n=249)$ & $(n=251)$ & $(n=251)$ & $(n=249)$ & $(n=500)$ \\
\hline Enteral & $28(22)$ & $21(17)$ & $27(22)$ & $23(19)$ & $55(22)$ & $44(18)$ & 48 (19) & $51(20)$ & $99(20)$ \\
\hline Parenteral & $42(34)$ & $44(35)$ & $45(36)$ & $42(34)$ & 87 (35) & $86(34)$ & $89(35)$ & 84 (34) & $173(35)$ \\
\hline Both & $16(13)$ & $21(17)$ & $13(10)$ & $20(16)$ & $29(12)$ & $41(16)$ & $34(14)$ & $36(14)$ & $70(14)$ \\
\hline None & $39(31)$ & $41(32)$ & $39(31)$ & $39(31)$ & $78(31)$ & $80(32)$ & $80(32)$ & $78(31)$ & $158(32)$ \\
\hline
\end{tabular}

$\mathrm{SD}=$ standard deviation. $\mathrm{IQR}=$ interquartile range.

Sample size and statistical analyses

The study was designed to detect a plausible reduction of reported infections (with glutamine) within the first 14 days, a $15 \%$ reduction from $50 \%$ to $35 \%$. About 340 patients would be required to detect this difference (80\% power, two sided 5\% significance level). To allow for loss of patients to follow-up during the six months for other outcomes, the trial recruitment target was inflated to 500 patients.

All outcomes were analysed on the basis of intention to treat (that is, all participants analysed within the group into which they were randomised irrespective of subsequent compliance with nutritional support). We also undertook a prespecified analysis of the primary outcomes in participants who received trial parenteral nutrition for at least five days. ${ }^{10}$

The principal comparisons were between $(a)$ all those randomised to glutamine formulation versus all those not allocated glutamine and $(b)$ all those randomised to extra selenium versus all those not allocated selenium. The primary outcome measures (infections and mortality) were analysed using logistic regression. Lengths of stay in the critical care or high dependency unit and in acute hospital were analysed with Cox proportional hazards models. Duration of treatment with antibiotics and modified SOFA score were analysed with the Mann-Whitney test.

All regression models included covariates indicating whether the patient had been allocated to receive glutamine or selenium and the minimisation variables (excluding trial centre). A two sided significance level of $5 \%$ was considered evidence of statistical significance, and corresponding confidence intervals were calculated. An interaction between glutamine and selenium was tested for by adding the interaction term to the model (two sided 5\% significance level).

Subgroup analyses, defined a priori, assessed severity of disease (Acute Physiology and Chronic Health Evaluation II (APACHE II) scores split by median score and the minimisation variables) by adding treatment subgroup interaction terms to the models. We used a two sided 1\% significance level to test the treatment by subgroup, interactions reflecting the more speculative nature of these analyses.

\section{RESULTS}

A total of 1134 patients were screened for participation from June 2004 to November 2008, of whom 506 did not meet trial inclusion criteria (fig 1). For 53 patients, trial parenteral nutrition was not immediately available, leaving 575 patients from whom consent was sought. The 502 who were randomised were located in 10 centres in Scotland.

\section{Baseline characteristics}

Baseline characteristics were well matched across groups (table 1). Participants had a mean (SD) age of 63.8 (14.9) years, 39\% were women, 89\% required level 3 care, 25\% were medical patients (defined as non-surgical cause for admission), and the median APACHE II score was 20 (interquartile range 16-25). At randomisation, 89\% were already receiving antibiotics, and $27 \%$ were undernourished. The nature of previous nutrition support was also well balanced 
Table $2 \mid$ Infection and mortality outcomes among 502 intensive care patients randomised to trial parenteral nutrition formulations. Values are numbers (percentages) unless stated otherwise

\begin{tabular}{|c|c|c|c|c|c|c|c|c|}
\hline \multirow[b]{3}{*}{ Outcome } & \multicolumn{8}{|c|}{ Trial parenteral nutrition formulations } \\
\hline & \multicolumn{4}{|c|}{ Individual formulations } & \multicolumn{4}{|c|}{ Combined groups } \\
\hline & $\begin{array}{c}\text { Glutamine } \\
(n=126)\end{array}$ & $\begin{array}{c}\text { Selenium } \\
(n=127)\end{array}$ & $\begin{array}{c}\text { Glutamine } \\
+ \text { selenium } \\
(n=124)\end{array}$ & $\begin{array}{l}\text { Neither } \\
(n=125)\end{array}$ & $\begin{array}{c}\text { Any } \\
\text { glutamine } \\
(n=250)\end{array}$ & $\begin{array}{l}\text { Any non- } \\
\text { glutamine } \\
(n=252)\end{array}$ & $\begin{array}{c}\text { Any } \\
\text { selenium } \\
(n=251)\end{array}$ & $\begin{array}{l}\text { Any non- } \\
\text { selenium } \\
(n=251)\end{array}$ \\
\hline \multicolumn{9}{|l|}{ New infections* } \\
\hline All infections: & $71(56)$ & $63(50)$ & $63(51)$ & $68(54)$ & $134(54)$ & $131(52)$ & $126(50)$ & $139(55)$ \\
\hline Odds ratio $(95 \% \mathrm{Cl})$ & - & - & - & - & \multicolumn{2}{|c|}{$1.07(0.75$ to 1.53$)$} & \multicolumn{2}{|c|}{$0.81(0.57$ to 1.15$)$} \\
\hline Confirmed infectionst: & $62(49)$ & $48(38)$ & $56(45)$ & $59(47)$ & $118(47)$ & $107(42)$ & $104(41)$ & $121(48)$ \\
\hline Odds ratio $(95 \% \mathrm{Cl})$ & - & - & - & - & $1.23(0.8$ & to 1.76$)$ & $0.75(0$ & to 1.08$)$ \\
\hline \multicolumn{9}{|l|}{ Mortality } \\
\hline $\begin{array}{l}\text { Within critical care orhigh } \\
\text { dependency unit: }\end{array}$ & $46(37)$ & $42(33)$ & $42(34)$ & $38(30)$ & $88(35)$ & $80(32)$ & $84(33)$ & $84(33)$ \\
\hline Odds ratio $(95 \% \mathrm{Cl})$ & - & - & - & - & \multicolumn{2}{|c|}{$1.17(0.80$ to 1.71$)$} & \multicolumn{2}{|c|}{1.004 (0.69 to 1.47$)$} \\
\hline Within 6 months: & $60(48)$ & $52(41)$ & $55(44)$ & $54(43)$ & $115(46)$ & $106(42)$ & $107(43)$ & $114(45)$ \\
\hline Odds ratio $(95 \% \mathrm{Cl})$ & - & - & - & - & $1.18(0.8$ & to 1.70$)$ & $0.89(0$ & to 1.29 ) \\
\hline
\end{tabular}

*Within 14 days after randomisation.

†Confirmed in accordance with Centers for Disease Control definition.

between groups. Only 11 participants had already received immune enhancing enteral or parenteral nutrition, which was stopped before entering the trial (see table $\mathrm{A}$ in appendix 1 on bmj.com). The median time in critical care units before randomisation was 2.6 days.

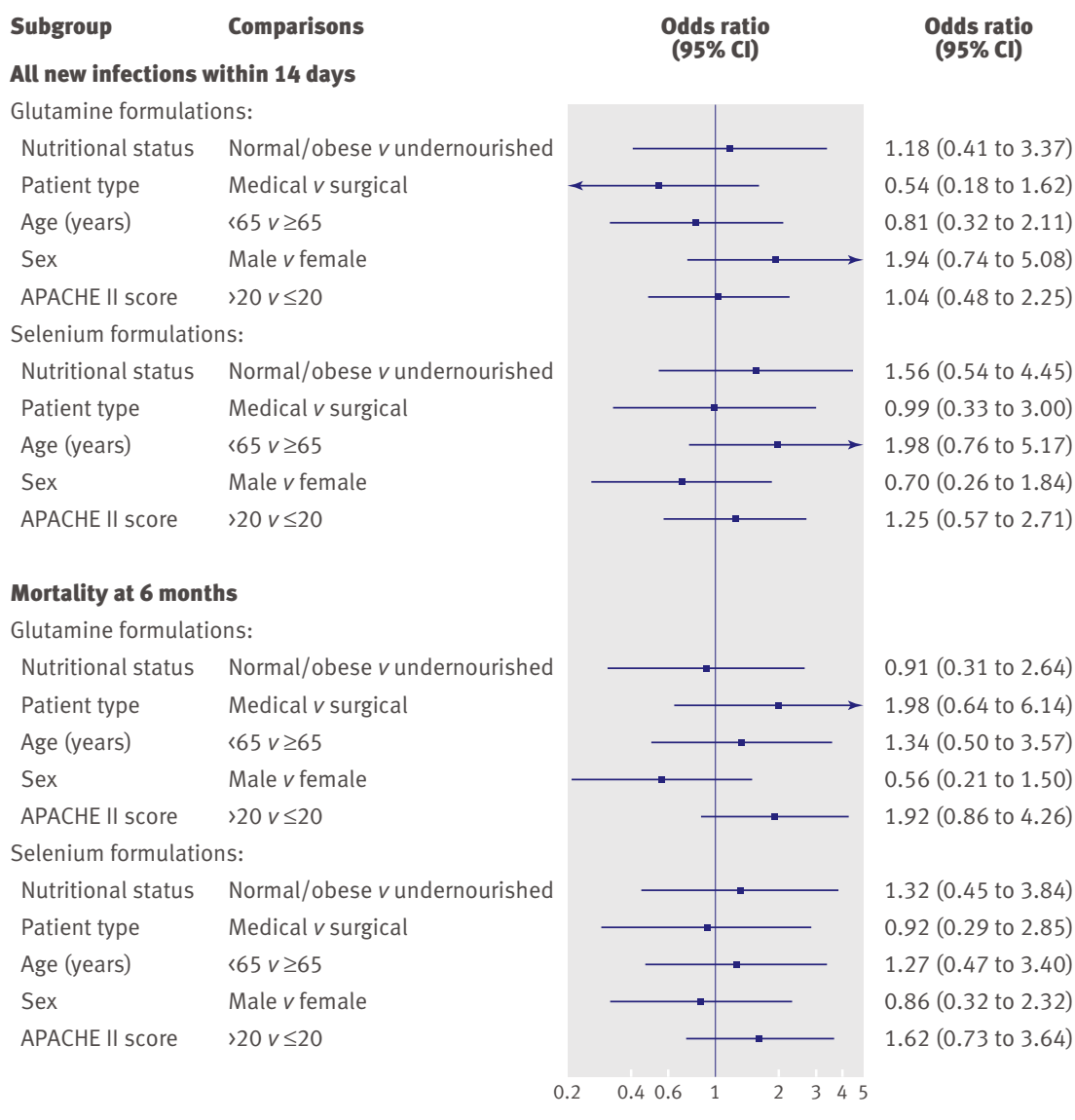

Fig 2 Subgroup analyses for infection and mortality outcomes among 502 intensive care patients randomised to trial parenteral nutrition formulations
Duration of trial parenteral nutrition use

The median duration of trial parenteral nutrition was 5.1 days for glutamine formulation only, 4.1 days for standard formulation plus selenium, 5.0 days for glutamine formulation plus selenium, and 4.7 days for standard formulation only.

Primary outcomes: new infections and mortality Nere infections

Table 2 shows the results for the primary outcome measures. Patients allocated to added selenium showed a non-significant decrease in the rate of any new infections in the next 14 days $(126 / 251$ (50\%) for selenium $v 139 / 251$ (55\%) for no selenium, odds ratio $0.81(95 \%$ confidence interval 0.57 to 1.15$) \mathrm{P}=0.24)$. There was no evidence of any beneficial effect from the glutamine formulation on new infections (134/ $250(54 \%)$ for glutamine $v 131 / 252(52 \%)$ for no glutamine, odds ratio 1.07 ( 0.75 to 1.53$) \mathrm{P}=0.71)$. There was no evidence of an interaction effect between glutamine and selenium (odds ratio 0.98 (0.48 to 2.00$) \mathrm{P}=0.96$ ).

The subgroup analyses showed no statistically significant $(1 \%$ level) interaction effects between the treatments and the subgroups (fig 2).

When the definition of an infection was restricted to the Centers for Disease Control criteria for confirmed infections, results were similar to those for all new infections for selenium (104/251 (41\%) for selenium $v 121 /$ 251 (48\%) for no selenium, odds ratio 0.75 (0.52 to 1.08$)$ $\mathrm{P}=0.12$ ) and for glutamine, which had a higher number $(118 / 250$ (47\%) for glutamine $v 107 / 252(42 \%)$ for no glutamine, odds ratio 1.23 (0.86 to 1.76$) \mathrm{P}=0.27)$. There was no statistical evidence of an interaction between treatments (odds ratio 1.28 (0.62 to 2.64$) \mathrm{P}=0.50$ ).

\section{Mortality}

Mortality within the critical care or high dependency units was slightly higher with glutamine formulations compared with standard formulations $(88 / 250$ (35\%) $v$ 


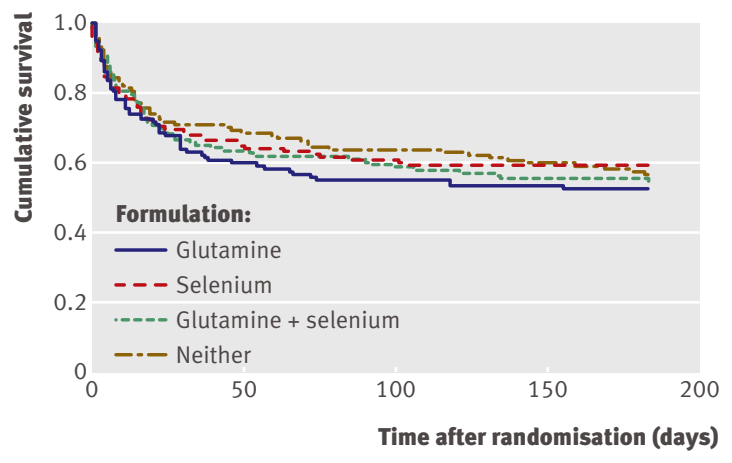

Fig 3 | Kaplan-Meier survival plot over six months after randomisation among 502 intensive care patients randomised to trial parenteral nutrition formulations

80/252 (32\%), odds ratio 1.17 (0.80 to 1.71 ) $\mathrm{P}=0.42$ ), but was unaffected by presence or absence of selenium (84/251 (33\%) v84/251 (33\%), odds ratio 1.004 (0.69 to 1.47) $\mathrm{P}=0.98$ ) (table 2). The interaction term between glutamine and selenium was also not significant (odds ratio 0.77 (0.36 to 1.65$) \mathrm{P}=0.50)$.

Six month mortality was lower in the groups with added selenium than in those without $(107 / 251(43 \%)$ $v 114 / 251(45 \%)$, odds ratio $0.89(0.62$ to 1.29$) \mathrm{P}=0.54)$ but was higher in the groups given the glutamine formulation than in those given standard formulation (115/ $250(46 \%) v 106 / 252(42 \%)$, odds ratio 1.18 (0.82 to 1.70) $\mathrm{P}=0.38$ ) (table 2). The interaction between glutamine and selenium was not significant (odds ratio 0.95 (0.46 to 1.97 ) $\mathrm{P}=0.88$ ). Figure 3 shows a plot of the Kaplan-Meier survival estimates over the first six months after randomisation for each treatment arm.

The subgroup analyses showed no significant interaction effects between the treatments and the subgroups (fig 2).

\section{Further analyses}

A priori analysis based on patients who had received a minimum of five days of trial parenteral nutrition showed that formulations with added selenium were associated with a significantly reduced proportion of participants with any new infection (odds ratio 0.53 (0.30 to 0.93 ) $\mathrm{P}=0.03$ ), but the glutamine formulations were not (odds ratio 0.99 ( 0.56 to 1.75$) \mathrm{P}=0.96$ ) (table 3 ). These results were similar for confirmed infections. For both mortality outcomes the effect sizes for both glutamine and selenium were not statistically significant (table 3).

The results for the primary outcomes were not affected by a post hoc analysis adjusting for sepsis at baseline (results not shown).

\section{Other outcome measures}

There was no evidence of a difference in length of stay, modified SOFA score, or antibiotic use with trial interventions (table 4). Serious adverse events were similar across the groups (10 cases each with the glutamine, selenium, and glutamine plus selenium formulations, and seven with the standard formulation only).

\section{DISCUSSION}

We assessed the effect of parenteral nutrition with glutamine or selenium, or both, in a pragmatic, factorial, rigorously designed randomised controlled trial in critically ill adults. Only the hospital research pharmacist knew the treatment allocation but facilitated clinical care by permitting individualisation of electrolyte, vitamin, and mineral supplementation. This study design achieved blinding of all data collection. ${ }^{11}$ The manufacture and initiation of parenteral nutrition by pharmacies did not differ from procedures outside

Table 3 |Infection and mortality outcomes among 502 intensive care patients randomised to trial parenteral nutrition formulations: restricted to those who received $\geq 5$ days of trial formulation. Values are numbers (percentages) unless stated otherwise

\begin{tabular}{|c|c|c|c|c|c|c|c|c|}
\hline \multirow[b]{3}{*}{ Outcome } & \multicolumn{8}{|c|}{ Trial parenteral nutrition formulations } \\
\hline & \multicolumn{4}{|c|}{ Individual formulations } & \multicolumn{4}{|c|}{ Combined groups } \\
\hline & $\begin{array}{l}\text { Glutamine } \\
(n=126)\end{array}$ & $\begin{array}{l}\text { Selenium } \\
(n=127)\end{array}$ & $\begin{array}{c}\text { Glutamine + } \\
\text { selenium } \\
(n=124)\end{array}$ & $\begin{array}{l}\text { Neither } \\
(n=125)\end{array}$ & $\begin{array}{c}\text { Any } \\
\text { glutamine } \\
(n=250)\end{array}$ & $\begin{array}{l}\text { Any non- } \\
\text { glutamine } \\
(n=252)\end{array}$ & $\begin{array}{l}\text { Any } \\
\text { selenium } \\
(n=251)\end{array}$ & $\begin{array}{c}\text { Any non- } \\
\text { selenium } \\
(n=251)\end{array}$ \\
\hline $\begin{array}{l}\text { Received } \geq 5 \text { days of trial } \\
\text { formulation }\end{array}$ & $n=64$ & $n=51$ & $n=60$ & $n=55$ & $n=124$ & $n=106$ & $n=111$ & $n=119$ \\
\hline \multicolumn{9}{|l|}{ New infections* } \\
\hline All infections: & $44(69)$ & $29(57)$ & $36(60)$ & $42(76)$ & $80(65)$ & $71(67)$ & $65(59)$ & $86(72)$ \\
\hline Odds ratio $(95 \% \mathrm{Cl})$ & - & - & - & - & \multicolumn{2}{|c|}{0.99 (0.56 to 1.75$)$} & \multicolumn{2}{|c|}{$0.53(0.30$ to 0.93$)$} \\
\hline Confirmed infectionst: & $38(59)$ & $23(45)$ & $32(53)$ & $39(71)$ & $70(56)$ & $62(58)$ & $55(50)$ & $77(65)$ \\
\hline Odds ratio $(95 \% \mathrm{Cl})$ & - & - & - & - & $0.99(0.5$ & to 1.72) & $0.52(0$. & to 0.90$)$ \\
\hline \multicolumn{9}{|l|}{ Mortality } \\
\hline $\begin{array}{l}\text { Within critical care or } \\
\text { high dependency unit: }\end{array}$ & $19(30)$ & $16(31)$ & $22(37)$ & $14(25)$ & $41(33)$ & $30(28)$ & $38(34)$ & $33(28)$ \\
\hline Odds ratio $(95 \% \mathrm{Cl})$ & - & - & - & - & \multicolumn{2}{|c|}{1.20 (0.67 to 2.15$)$} & \multicolumn{2}{|c|}{$1.40(0.79$ to 2.50$)$} \\
\hline Within 6 months: & $28(44)$ & $18(35)$ & $27(45)$ & $24(44)$ & $55(44)$ & $42(40)$ & $45(41)$ & $52(44)$ \\
\hline Odds ratio $(95 \% \mathrm{Cl})$ & - & - & - & - & $1.17(0.6$ & to 2.02 ) & $0.88(0$. & to 1.52 ) \\
\hline
\end{tabular}


Table $4 \mid$ Length of hospital stay, length of antibiotic treatment, and modified SOFA score among 502 intensive care patients randomised to trial parenteral nutrition formulations: intention to treat analysis. Values are medians (interquartile ranges) unless stated otherwise

\begin{tabular}{|c|c|c|c|c|c|c|c|c|}
\hline \multirow[b]{3}{*}{ Outcome } & \multicolumn{8}{|c|}{ Trial parenteral nutrition formulations } \\
\hline & \multicolumn{4}{|c|}{ Individual formulations } & \multicolumn{4}{|c|}{ Combined groups } \\
\hline & $\begin{array}{l}\text { Glutamine } \\
(n=126)\end{array}$ & $\begin{array}{l}\text { Selenium } \\
(n=127)\end{array}$ & $\begin{array}{c}\text { Glutamine + } \\
\text { selenium } \\
(n=124)\end{array}$ & Neither $(n=125)$ & $\begin{array}{l}\text { Any glutamine } \\
\qquad(n=250)\end{array}$ & $\begin{array}{l}\text { Any non- } \\
\text { glutamine } \\
(n=252)\end{array}$ & $\begin{array}{l}\text { Any selenium } \\
\quad(n=251)\end{array}$ & $\begin{array}{l}\text { Any non- } \\
\text { selenium } \\
(n=251)\end{array}$ \\
\hline \multicolumn{9}{|l|}{ Length of stay (days): } \\
\hline $\begin{array}{l}\text { In critical care or high } \\
\text { dependency unit: }\end{array}$ & $16.4(8.1-29.8)$ & $12.9(7.8-23.9)$ & $14.4(7.8-23.6)$ & $14.6(8.4-24.9)$ & $15.0(7.9-28.4)$ & $13.4(8.2-23.9)$ & $13.2(7.8-23.7)$ & $15.1(8.3-28.4)$ \\
\hline Hazard ratio $(95 \% \mathrm{Cl})$ & - & - & - & - & \multicolumn{2}{|c|}{$0.96(0.80$ to 1.14$)$} & \multicolumn{2}{|c|}{1.08 (0.91 to 1.29$)$} \\
\hline In acute hospital: & $33.8(14.7-58.1)$ & $28.3(14.7-50.3)$ & $31.2(14.6-53.4)$ & $27.3(15.2-52.9)$ & $32.5(14.7-55.6)$ & $28.2(15.1-52.4)$ & $29.8(14.7-52.4)$ & $31.2(15.1-57.8)$ \\
\hline Hazard ratio $(95 \% \mathrm{Cl})$ & - & - & - & - & \multicolumn{2}{|c|}{$0.89(0.75$ to 1.06$)$} & \multicolumn{2}{|c|}{1.05 (0.88 to 1.26$)$} \\
\hline Days of antibiotic use: & $2(0-11)$ & $0(0-8)$ & $0(0-14.5)$ & $0(0-8)$ & $0(0-14)$ & $0(0-8)$ & $0(0-10)$ & $0(0-10)$ \\
\hline $\begin{array}{l}\text { Mann-Whitney z score } \\
\text { (P value) }\end{array}$ & - & - & - & - & \multicolumn{2}{|c|}{$-1.69(0.09)$} & \multicolumn{2}{|c|}{$-0.80(0.42)$} \\
\hline $\begin{array}{l}\text { Modified SOFA score over one } \\
\text { week*: }^{*}\end{array}$ & $(n=72)$ & $(n=62)$ & $(n=71)$ & $(n=64)$ & $(n=143)$ & $(n=126)$ & $(n=133)$ & $(n=136)$ \\
\hline Score & $4(3-8)$ & $5(3-8)$ & $5(3-8)$ & $4(3-7.5)$ & $5(3-8)$ & $4(3-8)$ & $5(3-8)$ & $4(3-8)$ \\
\hline $\begin{array}{l}\text { Mann-Whitney z score } \\
\text { (P value) }\end{array}$ & - & - & - & - & \multicolumn{2}{|c|}{$-0.65(0.51)$} & \multicolumn{2}{|c|}{$-0.74(0.46)$} \\
\hline
\end{tabular}

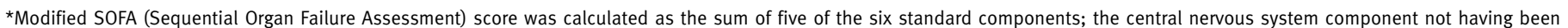
collected.

the trial. This trial is the largest to date with a sample size sufficient for rigorously testing our hypotheses.

Our primary analysis, on an intention to treat basis, showed no evidence of benefit for selenium or glutamine supplementation regarding a new infection. However, when the analysis was restricted to participants who received at least five days of trial parenteral nutrition there was a significant result in favour of selenium. There was no statistical evidence of benefit with regards to mortality.

\section{Comparison with other studies and guidelines}

Current guidance on nutrition support is available from ASPEN ${ }^{1213}$ and ESPEN ${ }^{14}$ (American and European Societies of Parenteral and Enteral Nutrition) and the Canadian critical care guidelines (updated 2009). ${ }^{4}$ ASPEN gives glutamine supplementation a grade $\mathrm{C}$ evidence level and states: "When parenteral nutrition is used in the critical care setting, consideration should be given to supplementation with parenteral glutamine" at a dose of $0.5 \mathrm{~g} / \mathrm{kg} /$ day. ${ }^{12}$ The ESPEN guidelines concur with the Canadian guidelines $\left(0.2-0.4 \mathrm{~g} / \mathrm{kg} /\right.$ day of L-glutamine) ${ }^{15}$ Our trial provided glutamine supplementation within the recommended dose range.

Clinical trials of selenium supplementation have used a wide range of doses. ${ }^{16}$ In a systematic review of antioxidant nutrients in critical illness, Heyland et al found that selenium supplementation (alone or in combination with other antioxidants) may be associated with a reduction in mortality (relative risk 0.59 (95\% confidence interval 0.32 to 1.08$)) .{ }^{1718}$

Strong biological arguments and clinical data indicate that a minimum dose is needed for both supplements before a "treatment effect" will occur. ${ }^{1819}$ However, many patients die or move to enteral nutrition support only a few days after starting parenteral nutrition. We therefore included (on the recommendation of the Trial Steering Committee) the prespecified analysis of patients who received at least five days of trial intervention.

SIGNET represents a substantial and important increase in evidence. ${ }^{40}$ When our data are added to current meta-analyses for glutamine supplementation the random effects risk ratio for mortality of $0.71(95 \%$ confidence interval 0.55 to 0.92$)$ changes to $0.80(0.62$ to 1.04 ) (see fig $\mathrm{A}$ in appendix 2 on bmj.com), and the risk ratio for new infection changes from 0.76 (0.62 to $0.93, \mathrm{I}^{2}=28 \%$ ) to $0.81\left(0.67\right.$ to $0.98, \mathrm{I}^{2}=43 \%$ ) (fig B in appendix 2). ${ }^{4}$

Similarly, when our trial data for selenium supplementation are entered into the current Cochrane systematic review ${ }^{21}$ the random effects risk ratio for mortality changes from $0.75\left(0.59\right.$ to $\left.0.96, \mathrm{I}^{2}=0 \%\right)$ to $0.86\left(0.74\right.$ to $1.00, \mathrm{I}^{2}=0 \%$ ) (fig $\mathrm{C}$ in appendix 2 ), and the risk ratio for new infections changes from 1.22 $\left(0.67\right.$ to $\left.2.23, \mathrm{I}^{2}=0 \%\right)$ to $0.93\left(0.79\right.$ to $1.09, \mathrm{I}^{2}=0 \%$ ) (fig $\mathrm{D}$ in appendix 2).

\section{Strengths and limitations of study}

Comprehensive national audit data for outcomes from Scottish critical care are publicly available (www.sic sag.scot.nhs.uk/), and, despite some variation between unit performances, an international audit of guideline compliance (Canadian Critical Care Nutrition Group) in 2007 and 2008 showed Scottish intensive care units compared favourably with intensive care units from around the world. These data indicate that SIGNET has strong external validity and generalisability of results.

The general methodological quality of a clinical trial can be gauged from three criteria: concealment of random treatment allocation, appropriate implementation of blinding, and presentation of an intention to 


\section{WHAT IS ALREADY KNOWN ON THIS TOPIC}

Patients requiring critical care have high mortality and commonly have gastrointestinal failure (when $150 \%$ of nutritional goals were met by the enteral route)

Parenteral nutrition is necessary for such patients, but it is unclear whether the parenteral nutrition should contain the amino acid glutamine or higher levels of the trace element selenium

\section{WHAT THIS STUDY ADDS}

Glutamine administered as part of parenteral nutrition did not decrease new infections nor did it reduce mortality

Selenium, $500 \mu \mathrm{g}$ daily as part of parenteral nutrition, significantly reduced new infections in the subset of patients who received it for $\geq 5$ days, but it did not affect mortality

treat analysis. Despite a CONSORT statement in $1996,{ }^{22}$ nutritional support studies are noted to be significantly poorer than sepsis trials in all aspects of methodological quality. ${ }^{23}$ However, SIGNET has considerable methodological strengths, including its factorial design. ${ }^{67}$

As in many parts of the world, nutritional support in the United Kingdom is not individualised for each patient to the exact protein and calorie requirement calculated from basal metabolic rate and allowing for activity or sepsis. The SIGNET parenteral nutrition formulation was designed to meet average estimated requirements for most patients. To avoid overfeeding patients with lower requirements, there was the facility to reduce the total amount infused. At the time of study design, the National Institute for Health and Clinical Excellence (NICE) concluded there was no evidence of improved outcomes from trying to tailor requirements accurately. This is a potential limitation of the findings of this study for critical care units that use these alternative approaches. Nevertheless, all groups were equally affected by this nutrition approach, which reflects clinical practice in most critical care units.

Patients' height and weight (actual or estimated) were collected in the trial. These data show that the dose of glutamine (about $0.25 \mathrm{~g}$ glutamine $/ \mathrm{kg}$ body weight for men and $0.3 \mathrm{~g} / \mathrm{kg}$ for women) was in keeping with contemporary guidelines on nutritional support. ${ }^{15}$ There may have been a small variation in the dose, but there was no signal within the results suggesting benefit from glutamine supplementation.

Nutritional assessment in critical care varies from the optimal ${ }^{24}$ to pragmatic bedside clinical assessment. As this was a pragmatic trial, we used a validated bedside screening tool, which reflects current practice in the UK.

The SIGNET trial followed routine clinical practices, so that its results would be generalisable. Thus, parenteral nutrition was provided based on clinical need and was made available as soon as practicable after the decision to start it, almost always within 24 hours. There was no prespecified time to start parenteral nutrition after admission to the critical care unit given the lack of evidence or consensus as to the best time to start parenteral nutrition. Many patients had already developed severe sepsis or septic shock and had established gastrointestinal failure as part of multiple organ failure before the decision to start parenteral nutrition. It is arguable whether earlier administration of either trial supplement might offer benefit in terms of supporting host defences. However, accurate prediction of multiple organ failure in hospital patients is not usually possible.

New infections were recorded for only the first 14 days. The intervention was set to a maximum of seven days, based on previous trial evidence, and it was considered that a longer lasting effect of the trial intervention was unlikely to be evident.

SIGNET is the largest and highest quality trial of parenteral nutrition conducted to date. It is pragmatic in design, with patient centred outcomes. The results of this trial were not expected, and they will energise considerable debate. The glutamine data are contrary to the beliefs of many clinicians that there is a conditional deficiency of glutamine in critical illness (an unproved construct) and that glutamine supplementation is beneficial.

Selenium is inexpensive, simple to deliver, and at the dose tested in SIGNET has low toxicity. If the exploratory results presented here were confirmed, it would provide a cost effective intervention in critically ill patients.

\section{Conclusion}

There may be a benefit from supplementing parenteral nutrition administered during critical illness with $500 \mu \mathrm{g}$ of selenium daily for at least five days, in terms of risk of new infection. There was no evidence of benefit with glutamine supplementation. Future research should confirm or refute the finding of benefit with five days of selenium supplementation.

We thank the Scottish Intensive Care Society, including Fiona MacKirdy, who gave their backing and support to SIGNET. We thank the pharmacy staff in aseptic services in the trial sites who ensured the smooth running of the trial, the hospital clinical staff, patients, and their best contacts who made this trial possible.

Contributors: The authors were the Trial Management Group for the SIGNET Trial Group.

Other members of the SIGNET Trial Group.

Data monitoring committee: GD Murray (chair), University of Edinburgh RJ Beale, St Thomas's Hospital, London; J Powell-Tuck, Royal London Hospital.

Independent steering committee: I Roberts (chair), London School of Hygiene and Tropical Medicine; M Singer, Bloomsbury Institute, University College London; SD Heys, University of Aberdeen; Morven Roberts (MRC observer).

Clinical trial office staff: $L$ Sinclair, University of Edinburgh; P Garden, AC Milne, GC McPherson, AM McDonald, D Barnett, D Collins, MM Kilonzo, M MacNeil, J Norrie, Health Services Research Unit, University of Aberdeen.

Hospital sites: Stirling Royal Infirmary - C Cairns (principal investigator), M Hawkins, F Mcllveney, A Longmate, K Ellis, J Grant, L Beverley, F Healey, C Pringle, K Morrison, F Struthers; Queen Margaret Hospital, Dunfermline - M McDougall (principal investigator), J Taylor, A Parker, A Timmins; Western General Hospital, Edinburgh-P Andrews (principal investigator), L Sinclair, H Milligan, M Naysmith, L Stanley, C Stein, R Hymers; Royal Infirmary of Edinburgh—S Mackenzie (principal investigator), T Walsh, K Everingham, F Frame, D Hope, C Maclver, P Ramsay, C Hannah, F McGill, I Thompson, J Merriweather; Aberdeen Royal Infirmary—D Noble (principal investigator), S Hall, J Addison, H Allan, J Mathieson, S Roughton, J Taylor, H Tennant, P Cooper, Dediare Utieyin, V Hailey, A Lightfoot, K McMullen, P Shand, P Sim; Glasgow Western Infirmary—S Binning (principal investigator), S Henderson, 
M Pollock, G Conkie; Ninewells Hospital, Dundee-C McMillan (principal investigator), A Mclntosh, S Carson, D Corner, F McIntyre, C Telfer; Dumfries and Galloway Royal Infirmary—D Williams (principal investigator), C Jardine, A Bell, K Douglas, C Johnston; Monklands Hospital, Airdrie—S Chohan (principal investigator), R MacKenzie, J Cummings; Raigmore Hospital, Inverness—I Skipsey (principal investigator), J Matheson, A Call, G Calder, E McDonald, L Aitchison, M McKenzie.

Other teams: University of Edinburgh -F Sloan, N Henderson, L Kellacher, N Kellock; Tayside Pharmaceuticals-J Cook, I Moffat, S Bath, B Millar; Fresenius-Kabi-G Carnegie, T Thakkur, R Smith; Oxford Nutrition-G Hardy.

Funding: A pilot trial was funded by the Chief Scientist Office of the Scottish Government Health Directorates, followed by funding from the Medical Research Council for the full trial. Funding was also provided by Fresenius-Kabi and Oxford Nutrition as unrestricted grants for the trial nutrition components. Health Services Research Unit is funded by the Chief Scientist Office of the Scottish Government Health Directorates. IC holds a MRC fellowship. AA was funded by a career scientist award of the Chief Scientist Office of the Scottish Government Health Directorates. The trial was managed in accordance with MRC guidelines and independent of industry. The trial was conducted under the auspices of independent trial steering and data monitoring committees. The views expressed are those of the authors alone.

Competing interests: None declared.

Ethical approval: The study was approved by the Multicentre Research Ethics Committee Scotland.

Data sharing: No additional data available at present, while economic evaluation is under way.

1 Allan R. 'Thousands starving in UK hospitals.' Clin Med 2007;7:429.

2 Doig GS, Heighes PT, Simpson F, Sweetman EA, Davies AR. Early enteral nutrition, provided within $24 \mathrm{~h}$ of injury or intensive care unit admission, significantly reduces mortality in critically ill patients: a meta-analysis of randomised controlled trials. Intensive Care Med 2010;36:1087-8.

3 Simpson F, Doig GS. Parenteral vs enteral nutrition in the critically ill patient: a meta-analysis of trials using the intention to treat principle. Intensive Care Med 2005;31:12-23.

4 Clinical Evaluation Research Unit. Critical care nutrition. 2010. www. criticalcarenutrition.com (accessed 8 Aug 2010).

5 Andrews PJ, Avenell A, Noble DW, Campbell MK, Battison CG, Croal BL, et al. Randomised trial of glutamine and selenium supplemented parenteral nutrition for critically ill patients. Protocol version 9, 19 February 2007, known as SIGNET (Scottish Intensive care Glutamine or seleNium Evaluative Trial). Trials 2007;8:25.

6 Lubsen J, Pocock SI. Factorial trials in cardiology: pros and cons. Eur Heart J 1994;15:585-8.
7 McAlister FA, Straus SE, Sackett DL, Altman DG. Analysis and reporting of factorial trials: a systematic review. JAMA 2003;289:2545-53.

8 Treasure T, MacRae KD. Minimisation: the platinum standard for trials? Randomisation doesn't guarantee similarity of groups; minimisation does. BMJ 1998;317:362-3.

9 Mead GE, Donaldson L, North P, Dennis MS. An informal assessment of nutritional status in acute stroke for use in an international multicentre trial of feeding regimens. Int / Clin Pract 1998;52:316-8.

10 Sheiner LB. Is intent-to-treat analysis always (ever) enough? Br / Clin Pharmacol 2002;54:203-11.

11 Altman DG. Statistics in medical journals: some recent trends. Stat Med 2000;19:3275-89.

12 ASPEN Board of Directors and the Clinical Guidelines Task Force. Guidelines for the use of parenteral and enteral nutrition in adult and pediatric patients. JPEN 2002;26(suppl 1):1-138SA.

13 Kochevar M, Guenter P, Holcombe B, Malone A, Mirtallo I. ASPEN statement on parenteral nutrition standardization. JPEN 2007;31:441-8.

14 Kreymann KG, Berger MM, Deutz NE, Hiesmayr M, Jolliet P, Kazandjiev G, et al. ESPEN guidelines on enteral nutrition: intensive care. Clin Nutr 2006;25:210-23.

15 Singer P, Berger MM, Van den Berghe G, Biolo G, Calder P, Forbes A, et al. ESPEN guidelines on parenteral nutrition: intensive care. Clin Nutr 2009;28:387-400.

16 Forceville X, Vitoux D, Gauzit R, Combes A, Lahilaire P, Chappuis P. Selenium, systemic immune response syndrome, sepsis, and outcome in critically ill patients. Crit Care Med 1998;26:1536-44.

17 Heyland DK, Dhaliwal R, Suchner U, Berger MM. Antioxidant nutrients: a systematic review of trace elements and vitamins in the critically ill patient. Intensive Care Med 2005;31:327-37.

18 Heyland DK. Selenium supplementation in critically ill patients: can too much of a good thing be a bad thing? Crit Care 2007:11:153.

19 Heyland DK, Dhaliwalm R, Day A, Drover J, Cote H, Wischmeyer P. Optimizing the dose of glutamine dipeptides and antioxidants in critically ill patients: a phase I dose-finding study. JPEN 2007;31:109-18.

20 Hennekens $\mathrm{CH}$, Demets $\mathrm{D}$. The need for large-scale randomized evidence without undue emphasis on small trials, meta-analyses, or subgroup analyses. JAMA 2009;302:2361-2.

21 Avenell A, Noble DW, Barr J, Engelhardt T. Selenium supplementation for critically ill adults. Cochrane Database Syst Rev 2004;4:CD003703.

22 Begg C, Cho M, Eastwood S, Horton R, Moher D, Olkin I, et al. Improving the quality of reporting of randomized controlled trials. The CONSORT statement. JAMA 1996;276:637-9.

23 Doig GS, Simpson F, Delaney A. A review of the true methodological quality of nutritional support trials conducted in the critically ill: time for improvement. Anesth Analg 2005;100:527-33.

24 Ziegler TR. Parenteral nutrition in the critically ill patient. N Engl / Med 2009;361:1088-97.

Accepted: 14 January 2011 